\title{
Research on the Correlation Between Economic Policy Uncertainty, Exchange Rate, and Stock Market -Empirical Analysis Based on DCC and BEKK- GARCH Model
}

\author{
Bin Liu ${ }^{1}$ Xiu-tong Liu ${ }^{1, *}$, Shuo Zhang ${ }^{1}$, Xiao-han $\mathrm{Yu}^{1}$ \\ ${ }^{1}$ School of Shipping Economics and Management, Dalian Maritime University, Dalian, Liaoning 116026, China \\ *Corresponding author. Email:18796462622@163.com
}

\begin{abstract}
Based on the monthly data from January 1995 to June 2018, taking the uncertainty index of China's economic policy developed by Scott Baker and others based on South China Morning Post, the exchange rate intermediate price of US dollar against RMB and Shanghai Securities Composite Index as the research objects, establishing three-variable DCC and BEKK-GARCH model to study the dynamic correlation and the volatility spillover effect among economic policy uncertainty, exchange rate and stock market. The results show that the correlation coefficient among the economic policy uncertainty, exchange rate and stock market fluctuates greatly and has time-varying characteristics, and the linkage between exchange rate and stock market is the highest, followed by the linkage between economic policy uncertainty and stock market, and the linkage between economic policy uncertainty and exchange rate is the lowest. In addition, there exists oneway volatility spillover effect from economic policy uncertainty to RMB exchange rate, two-way volatility spillover effect between economic policy uncertainty and stock market, and one-way volatility spillover effect from stock market to RMB exchange rate.
\end{abstract}

Keywords: economic policy uncertainty, exchange rate, stock market, DCC-GARCH model, BEKK-GARCH model

\section{INTRODUCTION}

Economic policy is an important means of "visible hand" in the market to regulate economic operations. The government has adopted various fiscal policies, monetary policies, trade policies, industrial policies to achieve macroeconomic control of economic development. The various uncertainties in the formulation and implementation of the policies are the uncertainties of economic policies. Since the financial crisis in the United States in 2008, various economic policies have been made by countries around the world to restore the economy, and the uncertainty of economic policies has entered the public eye. In the past two years, as the economy has entered a new normal and the complexity of the domestic and foreign economic environment has deepened, China has adopted an "active fiscal policy" and a "stable monetary policy". At the same time, we have focused on supply-side structural reform and adhered to the principle of " Three go, one drop, one supplement", so the uncertainty of economic policy has also increased. On July 21, 2005, China carried out the exchange rate reform and began to implement the floating exchange rate system. With the addition of the RMB to the SDR currency basket, and the subsequent introduction and implementation of a series of foreign exchange policies, as well as the continuous improvement of China's international status, the process of marketization and internationalization of the RMB exchange rate have greatly improved. Therefore, the RMB exchange rate issue has attracted extensive attention from all countries in the world. The stock market is called the "barometer" of the economy, and under the premise of the continuous internationalization of the RMB, the relationship between the RMB exchange rate and stock market fluctuation has become increasingly significant. Stock market and foreign exchange market are important parts of China's financial market, which reflect the overall operation of the economy. Therefore, on the one hand, fiscal and monetary policies promulgated by policy makers will have an impact on the exchange rate and stock market to a certain extent; on the other hand, stock market and foreign exchange market are also important basis for policy makers to judge economic trend and formulate economic policies.

Then, whether there is certain dynamic correlation among economic policy uncertainty, exchange rate and stock market, and whether there is direct or indirect volatility spillover effect among markets are the issues to be studied in this paper. It is of great practical significance to explain the volatility of financial market and provide certain theoretical basis for investors and policy makers. 


\section{LITERATURE REFERENCES}

Scholars have done little research on the correlation between economic policy uncertainty and exchange rate. Robert Krol [1] studied the impact of overall economic and economic policy uncertainty on exchange rates in 10 industrial and emerging economies since 1990. The study found that economic policy uncertainty directly increased the volatility of some currencies. Yosuke Kido [2] used the DCC-GARCH model, using data from January 2000 to December 2014, to analyze the spillover effect of the US economic policy uncertainty on the exchange rate. The study found that the correlation between US economic policy uncertainty and currency yields is always negative, while the correlation between US economic policy uncertainty and yen yields is always positive.

At the same time, some scholars have studied the correlation between economic policy uncertainty and the stock market. Through empirical tests, ĽUBOS̆ PÁSTOR $\&$ PIETRO [3] found that when the policy change is announced, the stock price will fall, and the greater the uncertainty, the greater the stock price will fall. Mingtao Wang and Lei Lu [4] used multiple regression models and through empirical tests found that changes in economic policies are the main cause of China's stock market volatility, and the impact on bull markets is stronger than that on bear markets.

In addition, many literatures have studied the correlation between exchange rate and the stock market. Kim K et al. [5] used monthly data from January 1974 to December 1998 as research object, and used cointegration test analysis to find that the $\mathrm{S} \& \mathrm{P}$ index has a negative correlation with real exchange rates, interest rates, and inflation. Zhiyong Cao [6] established a ternary VARBEKK-GARCH model for analysis. Research shows that there is a two-way volatility spillover effect between the Chinese stock market and the RMB exchange rate. At the same time, there is a one-way volatility spillover effect of the Chinese stock market on international crude oil prices. By analyzing previous studies, we can find that scholars mostly study the correlation between economic policy uncertainty and exchange rate, the correlation between economic policy uncertainty and the stock market, or the correlation between exchange rate and stock market. Little research has been done on the dynamic correlation among the three. Secondly, for the research of the volatility spillover effect among the three markets, scholars have mostly focused on studying the volatility spillover effect of one market on other markets, but less concerned about the two-way volatility spillover effect among markets or direct or indirect volatility spillover effect among several markets. Therefore, in view of the shortcomings in the existing literature, this article studied the dynamic correlation and volatility spillover effect among economic policy uncertainty, exchange rate, and the stock market, in an attempt to make up for the lack of previous research.

\section{MODEL AND DATA}

\subsection{Establishment of models}

Engle (2002) improved the constant correlation coefficient (CCC-GARCH) model proposed by Bollerslev (1990), and proposed the dynamic conditional correlation (DCCGARCH) model, which realized the time-variability of correlation coefficient on the basis of retaining the advantages of CCC model. In addition, the model simplifies the calculation of parameters and reduces the number of parameters, so it is suitable for studying the dynamic correlation among variables. The structure of DCC-GARCH model is as follows:

$$
\begin{gathered}
r_{t}=u_{t}+e_{t} \\
e_{t} \mid \varphi_{t-1} \sim N\left(0, H_{t}\right) \\
H_{t}=D_{t} R_{t} D_{t} \\
D_{t}=\operatorname{diag}\left(\sqrt{h_{11, t}}, \cdots, \sqrt{h_{n n, t}}\right) \\
R_{t}=\operatorname{diag}\left(\frac{1}{\sqrt{q_{11, t}}}, \cdots, \frac{1}{\sqrt{q_{n n, t}}}\right) Q_{t} \operatorname{diag}\left(\frac{1}{\sqrt{q_{11, t}}}, \cdots, \frac{1}{\sqrt{q_{n n, t}}}\right) \\
Q_{t}=(1-\alpha-\beta) \bar{Q}+\alpha \varepsilon_{t-1} \varepsilon_{t-1}^{\prime}+\beta Q_{t-1}
\end{gathered}
$$

Among them, $u_{t}$ is the conditional mean, $e_{t}$ is the residual term, $\varphi_{\mathrm{t}-1}$ is the information set at time $\mathrm{t}-1, \mathrm{R}_{\mathrm{t}}$ is the dynamic conditional correlation coefficient matrix, $D_{t}$ is the diagonal matrix with the condition standard deviation as the element, $Q_{t}$ is an $\mathrm{n} \times \mathrm{n}$ dimensional symmetric positive definite matrix, $\overline{\mathrm{Q}}$ is an unconditional variance matrix, and $\varepsilon_{\mathrm{t}-1}$ is obtained after normalizing the residual term $e_{t} . \alpha$ and $\beta$ are the coefficients of the previous standardized residual squared and the previous conditional variance in the multivariate GARCH model, and satisfy $\alpha>0, \beta>0, \alpha+\beta<1$.

Engle and Kroner (1995) proposed the multivariate GARCH model in the form of BEKK, which requires less parameters to be estimated and has more obvious economic significance. It can easily guarantee the positive characterization of the covariance matrix and is suitable for studying the volatility spillover effect among variables. The structure of BEKK-GARCH model is as follows:

$$
\begin{gathered}
y_{t}=u_{t}+e_{t} \\
e_{t} \mid \varphi_{t-1} \sim N\left(0, H_{t}\right) \\
H_{t}=C C^{\prime}+A \varepsilon_{t-1} \varepsilon^{\prime}{ }_{t-1} A^{\prime}+B H_{t-1} B^{\prime}
\end{gathered}
$$

Among them, formula $y_{t}$ is the mean value equation of the model, $e_{t}$ is the residual term, $\varphi_{t-1}$ is the information set at time $\mathrm{t}-1$, formula $H_{t}$ is the variance equation of BEKK form, $H_{t}$ is the $\mathrm{n} \times \mathrm{n}$ dimensional symmetric matrix, which represents the conditional variance matrix at time t, $A$ is the coefficient matrix of the $\mathrm{ARCH}$ term, $B$ is the coefficient moment of the GARCH term, and $\mathrm{C}$ is the constant coefficient matrix of the lower triangle.

As DCC-GARCH and BEKK-GARCH models have their respective applicability, this paper selects DCC-GARCH 
model to study the dynamic correlation among economic policy uncertainty, exchange rate and stock market, and selects BEKK-GARCH model to study the volatility spillover effect among economic policy uncertainty, exchange rate and stock market.

\subsection{Data selection and description}

This paper selects the monthly data from January 1995 to June 2018 as a sample, and selects China economic policy uncertainty index based on "South China Morning Post" on behalf of the Chinese economic policy uncertainty, data from the federal reserve bank of St. Louis federal reserve economic database. The monthly data of the USD / RMB mid-price is selected to represent the RMB exchange rate, and the monthly data of the Shanghai Securities Composite Index is used to represent the stock market. The data are from the Choice database, and the three time series are recorded as EPU, ER, and SZ. The research software used was Winrats8.

In order to explore the dynamic correlation and the volatility spillover effect among the China's economic policy uncertainty, the RMB exchange rate and the stock market, the author chooses to establish the DCC-GARCH model and BEKK-GARCH model for the research. First, in order to meet the modeling needs of the GARCH model and ensure the stability of the time series, logarithmic differences were made for the time series of China's economic policy uncertainty index, the monthly data of the USD / RMB mid-price and the Shanghai Securities Composite Index. The calculation method was: $\mathrm{R}_{\mathrm{t}}=100^{*}$

$\left(\mathrm{LnP}_{\mathrm{t}}-\mathrm{LnP}_{\mathrm{t}-1}\right)$, and a total of 294 data sets were obtained. The three yield series are recorded as REPU, RER, and RSZ respectively.

Before modeling, first conduct descriptive statistical analysis. The results are shown in table 1 .

Table 1 descriptive statistical results

\begin{tabular}{cccc}
\hline & REPU & RER & RSZ \\
\hline Mean & 0.542532 & -0.069959 & 0.568857 \\
\hline $\begin{array}{c}\text { Standard } \\
\text { deviation }\end{array}$ & 55.78857 & 0.642216 & 8.021684 \\
\hline Skewness & 0.063386 & 1.445794 & -0.143688 \\
\hline Kurtosis & 3.947351 & 16.82708 & 4.508302 \\
\hline JB test value & 11.15286 & 2436.167 & 28.78187 \\
\hline P value & 0.003786 & 0.000000 & 0.000001 \\
\hline
\end{tabular}

As can be seen from table 1, among the mean of the three time series, the RSZ is the largest. According to the results of standard deviation, the RER is the smallest, indicating the most gentle fluctuation. The REPU is the largest, indicating the most violent fluctuation and the highest risk. The skewness of the three yield series is not equal to zero, and their kurtosis is greater than 3 , which indicates that all three have obvious characteristic of "peak and thick tail". At the significance level of $1 \%$, all three JB test values show rejection of the null hypothesis, indicating that REPU, RER, and RSZ are not normally distributed. In summary, all three yield series have a large possibility of heteroscedasticity, which is the ARCH effect.

\section{EMPIRICAL ANALYSIS}

\subsection{ADF unit root test}

Due to the frequent occurrence of "pseudo-regression" in time series, in order to verify the stationarity of data and meet the requirements of model establishment, the ADF unit root test method is first used to test the stationarity of REPU, RER and RSZ. The test results are shown in table 2. Table 2 ADF test results

\begin{tabular}{cccc}
\hline variable & $\mathrm{t}$ statistic & $5 \%$ critical value & P value \\
\hline REPU & 15.81823 & -1.941921 & 0.000 \\
\hline RER & 11.97132 & -1.941914 & 0.000 \\
\hline RSZ & 16.01441 & -1.941914 & 0.000 \\
\hline
\end{tabular}

According to table 2, the data of REPU, RER and RSZ all reject the null hypothesis at the significance level of 5\%, indicating that the three time series are stationary, and the GARCH model can be used for test analysis.

\subsection{ARCH effect test}

The existence of ARCH effect in yield series is a prerequisite for DCC-GARCH and BEKK-GARCH model Therefore, before adopting GARCH model, three yield series should be tested for ARCH effect, and the test results are shown in table 3 .

Table 3 ARCH effect test results

\begin{tabular}{cccc}
\hline & REPU & RER & RSZ \\
\hline F statistic & 16.64646 & 6.117844 & 3.044999 \\
\hline P value & 0.0001 & 0.0140 & 0.0176 \\
\hline LM statistic & 15.85137 & 6.032769 & 11.88473 \\
\hline P value & 0.0001 & 0.0140 & 0.0182 \\
\hline
\end{tabular}

According to the $\mathrm{ARCH}$ effect test results, there are $\mathrm{ARCH}$ effects in all three yield series, which meets the modeling needs of DCC-GARCH and BEKK-GARCH model.

\subsection{DCC-GARCH model}

The DCC-GARCH model's modeling steps can be divided into two steps: first, the GARCH $(1,1)$ model of three yield series is established; second, the DCC-GARCH model is established based on the first step. The model parameter estimation results are shown in table 4 . 
Table 4 estimation results of DCC-GARCH model

\begin{tabular}{cccc}
\hline Parameter & REPU & \multicolumn{1}{c}{ RER } & RSZ \\
\hline Mean & -0.8068624 & $-0.0506185^{* *}$ & 0.1662211 \\
\hline $\mathrm{c}$ & $805.4704089^{* *}$ & $0.0033341^{* * *}$ & $3.8210796^{* *}$ \\
\hline$\alpha$ & $0.2678727 * * *$ & $0.0702190^{* * *}$ & $0.1835202^{* * *}$ \\
\hline$\beta$ & $0.4845978^{* * *}$ & $0.9506586^{* * *}$ & $0.7661382^{* * *}$ \\
\hline$\alpha$ & 0.0107062 \\
\hline$\beta$ & $0.9682809^{* * *}$ \\
\hline$\alpha+\beta$ & 0.9789871 \\
\hline Note: $* * *, * *$ and $*$ indicate significant levels at $1 \%, 5 \%$ and $10 \%$
\end{tabular}

According to the parameter estimation results of the DCC model, most parameters are significant at a significance level of $5 \%$, and the parameter estimation value of $\alpha$ is small, the parameter estimation value of $\beta$ is large, and $\alpha+$ $\beta$ is less than 1 , indicating that the correlation coefficient among REPU, RER and RSZ fluctuates greatly, and the market volatility is more persistent. Further estimation of the dynamic correlation coefficients among the three markets are shown in Figure 1.

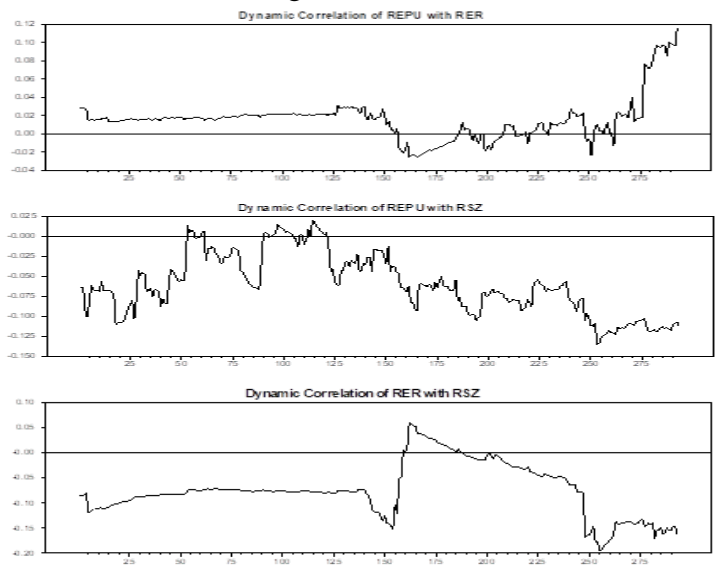

From the dynamic correlation coefficient charts of the three markets, it can be seen that the dynamic correlation coefficient among the China's economic policy uncertainty, the RMB exchange rate and the stock market fluctuates greatly, and has strong time-varying characteristics. Generally speaking, there is a clear positive correlation between economic policy uncertainty and the exchange rate, a clear negative correlation between economic policy uncertainty and the stock market, a clear negative correlation between the exchange rate and the stock market. The dynamic correlation coefficient between the exchange rate and the stock market is the largest, and the dynamic correlation coefficient between the economic policy uncertainty and the exchange rate is the smallest, which indicates that the linkage between the exchange rate and the stock market is the highest, the linkage between the economic policy uncertainty and the stock market is the second, and the linkage between the economic policy uncertainty and the exchange rate is the lowest.

\subsection{BEKK-GARCH model}

Based on the above analysis of the dynamic correlation among economic policy uncertainty, RMB exchange rate and stock market, this section establishes BEKK-GARCH model to further explore the volatility spillover effect among the three markets, and the results list in table 5 .

Figure 1 dynamic correlation coefficient

Table 5 estimation results of BEKK-GARCH model

\begin{tabular}{ccccc}
\hline coefficient & estimate & standard deviation & T statistic & P value \\
\hline $\mathrm{C}(1,1)$ & -0.00041023 & 3.63228089 & -0.0001129 & 0.99990989 \\
\hline $\mathrm{C}(2,1)$ & -0.00000006 & 0.00389894 & 0.00001529 & 0.99998780 \\
\hline $\mathrm{C}(2,2)$ & -0.00000004 & 0.00391576 & 0.00001140 & 0.99999090 \\
\hline $\mathrm{C}(3,1)$ & 0.00007260 & 0.51671201 & 0.00014049 & 0.99988790 \\
\hline $\mathrm{C}(3,2)$ & 0.00000051 & 0.55429046 & 0.00000092 & 0.99999927 \\
\hline $\mathrm{C}(3,3)$ & -0.00008881 & 0.55073059 & 0.00016125 & 0.99987134 \\
\hline $\mathrm{A}(1,1)$ & $0.09378968^{* * *}$ & 0.02810064 & 3.33763 & 0.00084495 \\
\hline $\mathrm{A}(1,2)$ & $0.00242392^{* * *}$ & 0.00016603 & -14.59917 & 0.00000000 \\
\hline $\mathrm{A}(1,3)$ & 0.00585886 & 0.00541732 & 1.08150 & 0.27947294 \\
\hline $\mathrm{A}(2,1)$ & 11.61070586 & 7.84979318 & -1.47911 & 0.13911098 \\
\hline $\mathrm{A}(2,2)$ & $2.33141539^{* * *}$ & 0.15328284 & -15.20989 & 0.00000000 \\
\hline $\mathrm{A}(2,3)$ & 1.82359923 & 1.58991334 & 1.14698 & 0.25138977 \\
\hline $\mathrm{A}(3,1)$ & $0.73998784^{* * *}$ & 0.25267215 & 2.92865 & 0.00340439 \\
\hline $\mathrm{A}(3,2)$ & $0.01266638^{* * *}$ & 0.00099231 & 12.76448 & 0.00000000 \\
\hline $\mathrm{A}(3,3)$ & $0.07573139^{* *}$ & 0.03186136 & -2.37690 & 0.01745862 \\
\hline $\mathrm{B}(1,1)$ & $0.92543437^{* * *}$ & 0.01772255 & 52.21790 & 0.00000000 \\
\hline $\mathrm{B}(1,2)$ & 0.00000074 & 0.00007449 & 0.00988 & 0.99211547 \\
\hline $\mathrm{B}(1,3)$ & $0.05849931^{* * *}$ & 0.00344421 & -16.98484 & 0.00000000 \\
\hline $\mathrm{B}(2,1)$ & -1.51432003 & 3.00287117 & -0.50429 & 0.61405710 \\
\hline $\mathrm{B}(2,2)$ & $0.23085459^{* * *}$ & 0.03348459 & 6.89435 & 0.00000000 \\
\hline $\mathrm{B}(2,3)$ & $0.87160525^{*}$ & 0.49959064 & 1.74464 & 0.08104775 \\
\hline $\mathrm{B}(3,1)$ & $2.61750879^{* * *}$ & 0.13340026 & 19.62147 & 0.00000000 \\
\hline $\mathrm{B}(3,2)$ & -0.00045312 & 0.00037668 & -1.20292 & 0.22900764 \\
\hline $\mathrm{B}(3,3)$ & $0.89936621^{* * *}$ & 0.01918089 & 46.88866 & 0.00000000 \\
\hline
\end{tabular}

Note: $* * *, * *$ and $*$ indicate significant levels at $1 \%, 5 \%$ and $10 \%$ 
uncertainty and stock market, and one-way volatility spillover effect from stock market to RMB exchange rate. This can be explained that the information of China's economic policy uncertainty fluctuation will be transmitted to the RMB exchange rate market and the stock market, and the information of stock market fluctuation will be transmitted to the economic policy uncertainty and the RMB exchange rate market.

According to the conclusion above, this paper puts forward the following suggestions: First, when formulating economic policies, the formulator should strengthen the stability of the policy and promptly disclose information to increase transparency; second, continue to improve the foreign exchange market and establish a sound RMB exchange rate formation mechanism; third, continue to deepen the reform of the stock market and reduce the government intervention; in the end, investors should establish a correct investment concept to prevent risks brought by economic event.

\section{REFERENCES}

According to table 6, at the significance level of $1 \%$, we accept the null hypothesis that there is no volatility spillover effect of the RMB exchange rate on the stock market, and reject the null hypothesis that there is no volatility spillover effect of the stock market on the RMB exchange rate. Therefore, through the Wald test, it can be known that there exists one-way volatility spillover effect from economic policy uncertainty to RMB exchange rate, two-way volatility spillover effect between economic policy uncertainty and stock market, and one-way volatility spillover effect from stock market to RMB exchange rate.

\section{CONCLUSION}

This paper establishs DCC-GARCH and BEKK-GARCH model to study the dynamic correlation and volatility spillover effect among economic policy uncertainty, exchange rate and stock market, and draws the following conclusions.

First, the economic policy uncertainty, exchange rate and stock market yield series have obvious characteristics of "peak and thick tail", all of which have the ARCH effect. Second, there is clear positive correlation between economic policy uncertainty and the exchange rate. There is clear negative correlation between economic policy uncertainty and the stock market, and there is clear negative correlation between the exchange rate and the stock market. The linkage between exchange rate and stock market is the highest, followed by the linkage between economic policy uncertainty and stock market, and the linkage between economic policy uncertainty and exchange rate is the lowest.

Third, there exists one-way volatility spillover effect from economic policy uncertainty to RMB exchange rate, twoway volatility spillover effect between economic policy
[1] Robert Krol. Economic Policy Uncertainty and Exchange Rate Volatility[J]. International Finance, 2014,17(2).

[2] Yosuke Kido. On the link between the US economic policy uncertainty and exchange rates[J]. Economics Letters,2016,144.

[3] L̆UBOS̆ PÁSTOR, PIETRO VERONESI. Uncertainty about Government Policy and Stock Prices[J]. The Journal of Finance,2012,67(4).

[4] Wang Mingtao, Lu lei, Song kai. Impacts of policy factors on volatility of stock markets[J]. Journal of Management Sciences in China,2012,15(12).

[5] Kim K, Mukherjee T K et al. Dollar exchange rate and stock price: evidence from multivariate cointegraion and error correction model[J]. Review of Financial Economics,2003,12(3).

[6] Cao Zhiyong. Research on the Dynamic Relationship between China's Stock Market, Exchange Rate and International Crude Oil Price[D]. China University of Geosciences (Beijing), 2017. 